\title{
Myeloid-derived suppressor cells are elevated in patients with psoriasis and produce various molecules
}

\author{
DAN ILKOVITCH ${ }^{1}$ and LAURA K. FERRIS ${ }^{2}$ \\ ${ }^{1}$ Department of Dermatology, Cleveland Clinic Florida, Weston, FL 33331; \\ ${ }^{2}$ Department of Dermatology, University of Pittsburgh Medical Center, Pittsburgh, PA 15213, USA
}

Received June 7, 2016; Accepted July 22, 2016

DOI: $10.3892 / \mathrm{mmr} .2016 .5685$

\begin{abstract}
Psoriasis is a debilitating chronic inflammatory disease. In addition to the characteristic effects on the skin, chronic inflammation associated with the disease is recognized to contribute to cardiovascular, hepatic and renal comorbidities. Immature myeloid regulatory cells, known as myeloid-derived suppressor cells (MDSCs), have been demonstrated to accumulate in various diseases and chronic inflammatory states, including inflammatory bowel disease and various types of cancer. The results of the present study, obtained using flow cytometry and cell culture analysis of peripheral blood mononuclear cells from psoriasis and healthy patients, revealed that MDSC levels are significantly increased in the blood of patients with psoriasis compared with healthy controls. Furthermore, these cells are capable of producing various molecules, including matrix metalloproteinase-9 and-1, interleukin-8, growth-related oncogene, and monocyte chemoattractant protein 1 . These molecules may recruit additional immune cells involved in the pathogenesis of the disease, and contribute to the chronic inflammatory state in these patients. Therefore, MDSCs, which have various immune regulatory functions, may contribute to the pathogenesis of psoriasis as a systemic inflammatory disease.
\end{abstract}

\section{Introduction}

Psoriasis is a potentially debilitating disease, which due to chronic inflammation, may have effects on other organ systems in addition to the skin, resulting in increased risk of cardiovascular, liver and renal disease (1-4). Analyses of immune cells circulating in the blood of patients with psoriasis have revealed unique gene signatures compared with healthy controls, providing evidence of the systemic nature

Correspondence to: Dr Dan Ilkovitch, Department of Dermatology, Cleveland Clinic Florida, 2950 Cleveland Clinic Blvd., Weston, FL 33331, USA

E-mail: dilkovitch@med.miami.edu

Key words: psoriasis, inflammation, myeloid-derived suppressor cells, immunomodulation, cytokines of the disease (5). Abnormal immune responses in the skin are involved in the pathophysiology of psoriasis, resulting in inflammation and increased epidermal proliferation. Therapies that block T-cell proliferation or specific therapies that block cytokines, including tumor necrosis factor (TNF), interleukin (IL)-17, IL-12 and IL-23, have been demonstrated to be effective in the treatment of psoriasis patients. The various cytokines involved in this aberrant immune-mediated disease are produced by $\mathrm{T}$ cells, myeloid cells including dendritic cells and macrophages, and epidermal keratinocytes. Although it may appear counterintuitive to have immunoregulatory cells in autoimmune and inflammatory diseases, chronic inflammatory responses initiate an increase of regulatory immune cells to attempt to downregulate the response. These immunoregulatory cells may produce various molecules that alter the inflammatory milieu (6).

Myeloid-derived suppressor cells (MDSCs), are a population of immature myeloid cells with an immune regulatory role. Myeloid-derived suppressor cells originate from common myeloid progenitors in the bone marrow; however, under inflammatory conditions an aberrant sustained myelopoiesis may result in the accumulation of immature myeloid cells. These myeloid cells then deviate from the standard path of differentiation depending on the inflammatory milieu. This deviation may lead to the activation of immunoregulatory pathways, including activation of the enzymes arginase 1 and nitric oxide synthase 2 , and production of reactive oxygen species. These metabolic pathways have been demonstrated to affect every arm of the immune system $(7,8)$. MDSC suppress T-cell proliferation (9), inhibit natural killer (NK) cell cytotoxicity $(10)$, modulate macrophage polarization $(11,12)$ and induce the development of regulatory T cells (13). MDSCs have been demonstrated to modulate the immune response to various diseases, including numerous types of cancer (14-19), inflammatory bowel disease (IBD) (20), traumatic stress (21), burns $(22)$, infections $(23,24)$ and transplantation $(25)$. In addition, a recent study has indicated that MDSCs are elevated in patients with psoriasis (26). MDSCs under certain conditions may differentiate into endothelial cells, macrophages, dendritic cells or neutrophils $(27,28)$. In various human disease states, including psoriasis, MDSCs have been identified as human leukocyte antigen (HLA)-DR ${ }^{\mathrm{lo} /}$-cluster of differentiation (CD) $15^{+}$(granulocytic MDSC) and HLA-DR ${ }^{\mathrm{lo} /-} \mathrm{CD} 14^{+}$ (monocytic MDSC) $(26,29)$. 
The aim of the present study was to assess circulating MDSC levels in the peripheral blood of patients with psoriasis relative to healthy controls. Furthermore, the production of cytokines, chemokines and matrix metalloproteinases (MMPs) by MDSCs, which may contribute to the inflammatory state, was investigated.

\section{Materials and methods}

Blood donors and sample preparation. A protocol for informed consent was developed with the support of the Clinical \& Translational Science Institute at the University of Pittsburgh (Pittsburgh, PA, USA), and the present study was approved by the Internal Review Board of the University of Pittsburgh. Healthy controls or patients with psoriasis covering $>10 \%$ body surface area, and who did not have viral hepatitis, human immunodeficiency virus or an autoimmune disease, and were not on any immune-modulating systemic medications (for example, prednisone, biologics, methotrexate, cyclosporine or retinoids) were enrolled in the present study following the receipt of signed informed consent $(\mathrm{n}=11$ healthy controls; $\mathrm{n}=15$ patients with psoriasis). The average age of patients was 38 years for healthy controls and 48 years for psoriasis patients, which was not significantly different $(\mathrm{P}=0.080)$. The average body mass index of patients was 25 for healthy controls and 26 for psoriasis patients, which was not significantly different $(\mathrm{P}=0.890)$. The healthy control group consisted of 5 males and 6 females, and the psoriasis group consisted of 5 males and 10 females. Blood (up to $20 \mathrm{ml}$ per draw) was collected in heparinized tubes (BD Biosciences, San Jose, CA, USA) and processed within 4 h by diluting blood with phosphate-buffered saline (PBS) to $40 \mathrm{ml}$. Diluted blood was underlaid with $10 \mathrm{ml}$ Ficoll-Paque Premium 1.084 density gradient medium (Thermo Fisher Scientific, Inc., Waltham, MA, USA). Samples were centrifuged at $300 \times g$, at room temperature and without brake for $20 \mathrm{~min}$. The peripheral blood mononuclear cell (PBMC)-containing interphase layer was removed, washed with PBS, and resuspended in Recovery $^{\mathrm{TM}}$ cell culture freezing medium (Invitrogen; Thermo Fisher Scientific, Inc.) and aliquoted into cryovials. Samples were placed into a $-80^{\circ} \mathrm{C}$ freezer in a Mr. Frosty container (Thermo Fisher Scientific, Inc.) to ensure controlled cooling at $1^{\circ} \mathrm{C} /$ minute. Samples were transferred to liquid nitrogen for storage after 1 week. Prior to analysis, stored samples were thawed rapidly in a $37^{\circ} \mathrm{C}$ water bath.

Flow cytometry. Cells (1x $10^{6}$ per tube) were Fc blocked for $5 \mathrm{~min}$, using $2 \mu 1$ anti-CD32 (catalog no. 555447; BD Biosciences), and the following antibodies were added in magnetic-activated cell sorting (MACS) separation buffer (Miltenyi Biotec, Inc., Auburn, CA, USA): Anti-HLA-DR-phycoerythrin (PE; G46-6; catalog no. 555812), anti-CD14-PacificBlue (M5E2; catalog no. 558121), anti-CD15-allophycocyanin (APC; HI98; catalog no. 551376), anti-CD3-fluorescein isothiocyanate (FITC; SK7; catalog no. 349201), anti-CD56-FITC (NCAM16.2; catalog no. 340410), anti-CD20-FITC (L27; catalog no. 347673), anti-CD19-FITC (SJ25C1; catalog no. 340719), anti-CD4-PacificBlue (RPA-T4; catalog no. 561844) and anti-CD8-BV786 (RPA-T8; catalog no. 563823), purchased from BD Biosciences. Antibodies were incubated for $30 \mathrm{~min}$ at $4^{\circ} \mathrm{C}$ at concentrations indicated by the manufacturer. Cells were subsequently fixed with $1 \%$ paraformaldehyde in MACS separation buffer, and samples were analyzed on an LSR II (BD Biosciences). One aliquoted and cryopreserved healthy control blood sample served as an interexperimental control in serial flow cytometric analyses. Granulocytic MDSCs were defined as HLA-DR ${ }^{\mathrm{lo} /} \mathrm{CD} 15^{+}$, and monocytic MDSCs as HLA-DR ${ }^{\mathrm{lo} /} \mathrm{CD} 14^{+}$, as described previously (29).

Suppression assay and MDSC purification. Patient samples were thawed and $3 \times 10^{6}$ PBMCs were removed and labeled with $1 \mu \mathrm{mol} / 1$ 5-(and 6) carboxyfluorescein diacetate succinimidyl ester (CFSE; Invitrogen; Thermo Fisher Scientific, Inc.) for $15 \mathrm{~min}$ at $37^{\circ} \mathrm{C}$, according to the manufacturer's protocol. The remaining thawed unlabeled PBMCs were resuspended in MACS separation buffer and labeled with anti-HLA-DR microbeads (Miltenyi Biotec, Inc.). MACS was then performed on LS columns (Miltenyi Biotec, Inc.) according to the manufacturer's protocol. HLA-DR depleted cells were then labeled with anti-CD14 microbeads and separated on columns to obtain $\mathrm{HLA}_{-\mathrm{DR}}{ }^{\mathrm{lo} / \mathrm{CD}} 14^{+}$cells. Flow through cells (HLA-DR ${ }^{\mathrm{lo} /} \mathrm{CD} 14$ cells) were then labeled with anti-CD3 microbeads (Miltenyi Biotec, Inc.) and separated to obtain $\mathrm{CD}^{+}$cells. Cells were resuspended in AIM-V medium (Invitrogen; Thermo Fisher Scientific, Inc.) supplemented with $2 \mathrm{mM}$ Glutamax (Invitrogen; Thermo Fisher Scientific, Inc.), $50 \mathrm{U} / \mathrm{ml}$ penicillin $/ 50 \mu \mathrm{g} / \mathrm{ml}$ streptomycin (Invitrogen; Thermo Fisher Scientific, Inc.) and $500 \mathrm{U} / \mathrm{ml}$ IL-2 (BD Biosciences). Culture plates (96-well) were precoated overnight with $50 \mu \mathrm{l} /$ well $1 \mu \mathrm{g} / \mathrm{ml}$ anti-CD3 (BD Biosciences). CFSE-labeled PBMCs were plated at $2 \times 10^{5}$ cells/well and MDSCs were added at various ratios. For stimulation, $2.5 \mu \mathrm{g} / \mathrm{ml}$ anti-CD28 (BD Biosciences) was added to culture wells in addition to the plate bound anti-CD3. Final volume was $300 \mu \mathrm{l} /$ well. On day 6 of culture, cells were harvested, labeled with anti-CD4 and anti-CD8 antibodies as aforementioned, and CFSE dilution was analyzed by flow cytometry.

Cytokine analysis. Cells were purified and cultured as aforementioned ( $2 \times 10^{5} /$ well in 96-well plates) for 2 days, and then supernatants were collected and stored until analysis. Supernatants were analyzed by Luminex bead-based technology at the Luminex Core Facility at the University of Pittsburgh Cancer Institute (Pittsburgh, PA, USA).

Statistical analysis. Data are expressed as mean \pm standard error. Groups were compared using two-tailed t-tests. $\mathrm{P}<0.05$ was considered to indicate a statistically significant difference.

\section{Results}

MDSC levels in the circulation of patients with psoriasis. PBMCs were isolated from patients with psoriasis and healthy controls. There were no statistically significant differences in age or body mass index between the two groups. Flow cytometry was performed to analyze MDSC levels within the PBMCs by gating on non-lymphocytes, cells negative for T, B, and NK cell markers (CD3-CD19-CD20-CD56-), and analyzing CD14, CD15 and HLA-DR (Fig. 1A). A significant increase was

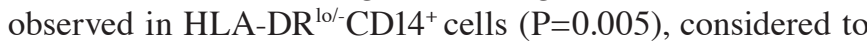
be monocytic MDSCs, and HLA-DR ${ }^{\mathrm{lo}} / \mathrm{CD} 15^{+}$cells $(\mathrm{P}=0.004)$, considered to be granulocytic MDSCs, in patients with psoriasis 


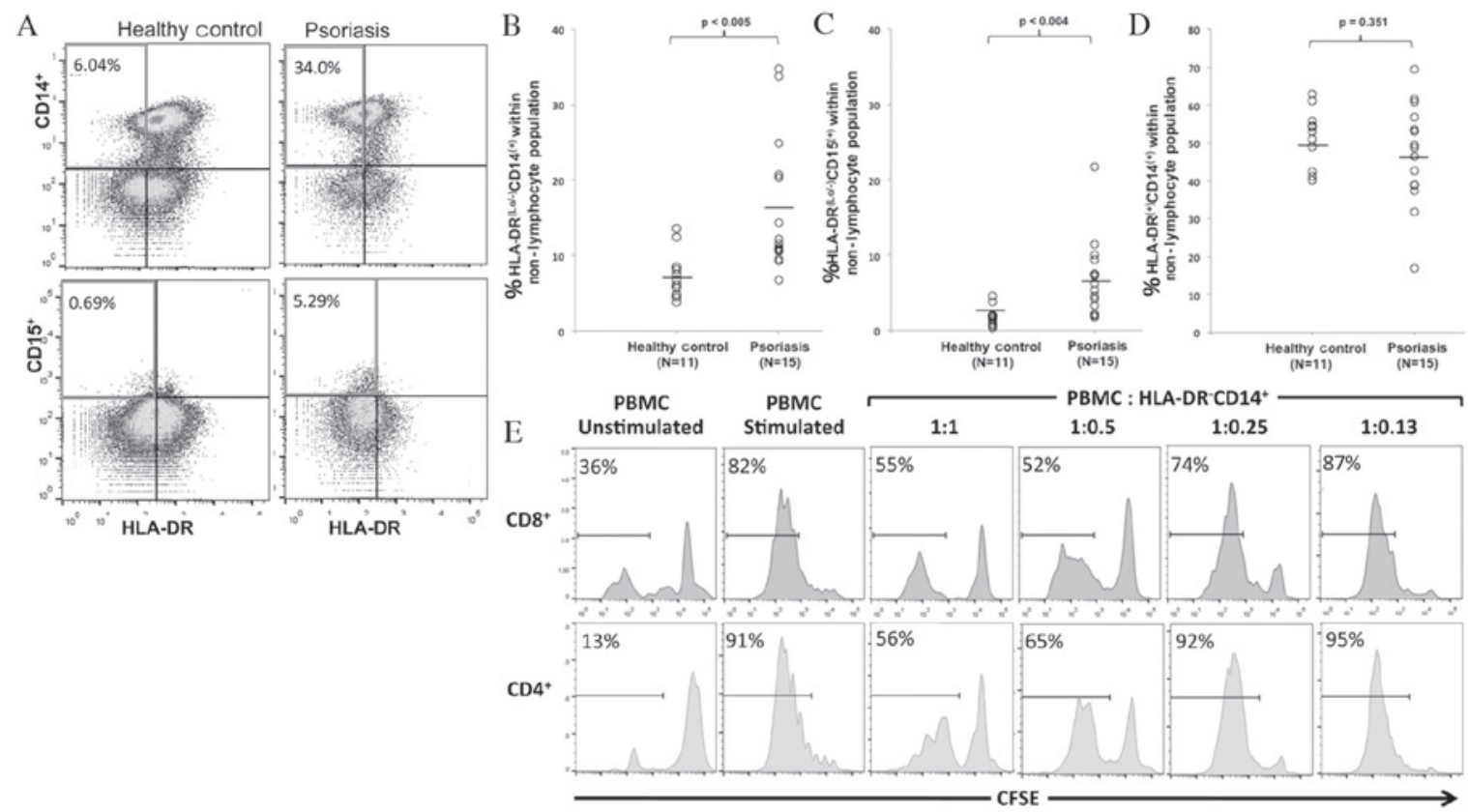

Figure 1. MDSCs are elevated in peripheral blood from patients with psoriasis. (A) Psoriasis and healthy control PBMCs negative for the lymphocyte markers CD3, CD19, CD20 and CD56 were analyzed for HLA-DR, CD14 and CD15 expression. PBMCs isolated from patients with psoriasis had increased percentages of (B) HLA-DR ${ }^{\mathrm{lo} /} \mathrm{CD} 14^{+}$and (C) HLA-DR ${ }^{\mathrm{lo} /} \mathrm{CD} 15^{+}$cells, compared with healthy controls. (D) No significant differences were observed in the percentage of HLA-DR ${ }^{+} \mathrm{CD} 14^{+}$cells between the two groups. (E) CFSE-labeled PBMCs were stimulated with anti-CD3 and -CD28 in the presence or absence of autologous MDSCs at the indicated ratios. CFSE dilution indicating proliferation is presented following gating on $\mathrm{CD}^{+}{ }^{+}$or $\mathrm{CD} 8^{+} \mathrm{T}$ cells. CD $4^{+}$and $\mathrm{CD} 8^{+} \mathrm{T}-$-cell proliferation was suppressed by MDSCs in a dose-dependent manner. A representative example of three experiments is presented. MDSCs, myeloid-derived suppressor cells; PBMCs, peripheral blood mononuclear cells; CD, cluster of differentiation; HLA, human leukocyte antigen; CFSE, 5-(and 6) carboxyfluorescein diacetate succinimidyl ester.

compared with healthy controls (Fig. 1B and C). There was no significant difference in the percentage of mature monocytes (HLA-DR $\left.{ }^{+} \mathrm{CD} 14^{+}\right)$between the two groups $(\mathrm{P}=0.351)$ (Fig. 1D).

Circulating MDSCs are properly identified by phenotype and function. MDSCs are defined by their suppression of T-lymphocyte proliferation in response to various stimuli in vitro, in addition to phenotypic markers. As granulocytic MDSCs exist in relatively low numbers, are difficult to isolate and have been demonstrated to lose their regulatory function following cryopreservation (30), the regulatory function of HLA-DR ${ }^{10 /-} \mathrm{CD} 14^{+}$cells was analyzed. MDSCs from the PBMCs of patients with psoriasis were isolated, and co-cultured at various ratios with autologous CFSE-labeled PBMCs activated with anti-CD3 and -CD28. CFSE dilution in activated $\mathrm{CD}^{+}{ }^{+}$and $\mathrm{CD} 8^{+} \mathrm{T}$ cells was analyzed following 6 days of culture, and a representative experiment revealed that $\mathrm{CD}^{+}$and $\mathrm{CD}^{+}$T-cell proliferation was suppressed by MDSCs in a dose-dependent manner (Fig. 1E). At a 1:1 $\mathrm{PBMC}$ to $\mathrm{MDSC}$ ratio, $\mathrm{CD}^{+}$and $\mathrm{CD}^{+}{ }^{+} \mathrm{T}$-cell proliferation is greatly reduced compared with $\mathrm{T}$ cell proliferation in the absence of MDSC or in the presence of low numbers of MDSC (ratio 1:0.13). This in vitro regulatory function indicates that the population identified in the present study is that described previously as MDSCs (29).

Analysis of molecules produced by MDSCs. MDSCs were isolated from patients with psoriasis and were cultured in vitro in the absence of polyclonal stimulation. Culture supernatants were then analyzed. The following molecules were produced by unstimulated MDSCs: MMP9, MMP1, IL-8, growth-related oncogene (GRO) and monocyte chemoattractant protein (MCP)-1 (Fig. 2). The following molecules were not produced in significant quantities by unstimulated MDSCs: IL-1 $\beta$, IL-2, IL-4, IL-5, IL-6, IL-7, IL-9, IL-10, IL-12p70, IL-13, IL-15, IL-17A, IL-17E, IL-17F, IL-21, IL-22, IL-23, IL-27, IL-28A, IL-31, IL-33, interferon (IFN) $\alpha$, IFN $\gamma$, IFN $\gamma$-induced protein 10, FMS-like tyrosine kinase 3 ligand, fractalkine, granulocyte colony-stimulating factor (CSF), granulocyte-macrophage CSF, MCP-3, macrophage-derived chemokine, macrophage inflammatory protein (MIP)-1 $\alpha$, MIP-1 $\beta$, MIP-3 $\alpha$, platelet-derived growth factor (PDGF)-AA, PDGF-BB, regulated on activation, normal $\mathrm{T}$ cell expressed and secreted, TNF $\alpha$, TNF $\beta$, transforming growth factor $\alpha$, vascular endothelial growth factor, sCD40L, MMP2, MMP3, MMP7, MMP8, MMP10, MMP12 and MMP13 (Fig. 2 and data not shown). MDSCs cultured under various in vitro conditions may produce these molecules; however, the aim of the present study was to determine which molecules are produced at baseline by circulating MDSCs.

\section{Discussion}

MDSCs have been identified in various skin diseases, including melanoma (15), squamous cell carcinoma (31), radiation and burn injury (32), contact dermatitis (33), atopic dermatitis $(6,34)$, and a recent study reported elevated levels of MDSCs in patients with psoriasis (26). The aim of the present study was to determine if MDSCs are elevated in the circulation of patients with psoriasis. The results 


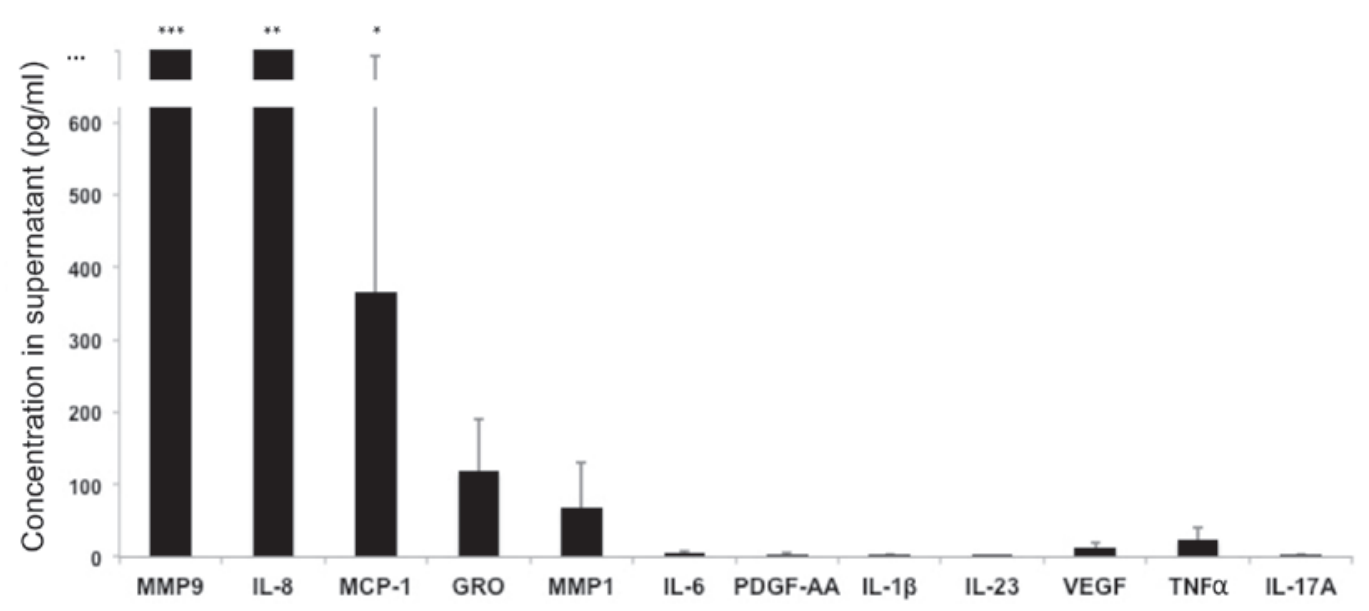

Figure 2. MDSCs produce various molecules. MDSCs were cultured in vitro in the absence of polyclonal activation, and culture supernatants were analyzed. Data are expressed as the mean \pm standard deviation ( $\mathrm{n}=7$ patients). MMP9, MMP1, IL-8, GRO and MCP-1 were produced by unstimulated MDSCs.

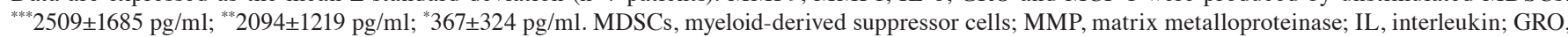
growth-related oncogene; MCP, monocyte chemoattractant protein; PDGF, platelet-derived growth factor; VEGF, vascular endothelial growth factor; TNF, tumor necrosis factor.

demonstrated that granulocytic and monocytic MDSC subtypes were significantly increased in patients with psoriasis compared with healthy controls. MDSCs were identified by phenotype (HLA-DR ${ }^{\mathrm{lo} /-} \mathrm{CD} 15^{+}$for granulocytic MDSC and HLA-DR ${ }^{\mathrm{lo} /}-\mathrm{CD} 14^{+}$for monocytic MDSC) and function (suppression of $\mathrm{CD}^{+}$and $\mathrm{CD} 8^{+} \mathrm{T}$ cells). This suppression of $\mathrm{T}$ cells may initially appear counterintuitive, as psoriasis is associated with overactive $\mathrm{T}$ cells, and therapeutic strategies for patients with psoriasis may involve suppressing $\mathrm{T}$ cell activity. However, in IBD, a disease that may similarly be treated through T-cell suppression, MDSCs were demonstrated to be elevated, but markedly increased levels were required in vivo to successfully suppress the disease $(20,35,36)$. In contrast to in vitro studies, in vivo circulating MDSCs may not successfully interact with pathogenic $\mathrm{T}$ cells, they may differentiate into other cell types, or they may suppress only certain T-cell subtypes. A recent study, which demonstrated elevated levels of MDSCs in patients with psoriasis, also demonstrated that MDSCs from healthy controls and psoriatic patients induced conversion of $\mathrm{T}$ effector cells to $\mathrm{T}$ regulatory cells (26). However, MDSCs from patients with psoriasis induced $\mathrm{T}$ regulatory cells that were markedly less suppressive, and thus less able to regulate the inflammatory response.

The present study hypothesized that MDSCs in patients with psoriasis may contribute to the inflammatory state, and have additional roles to the regulation of T-cell activity. Previous reports have revealed that myeloid cells from the peripheral blood of patients with psoriasis produce increased levels of IL-1 $\beta$, IL- 8 , TNF- $\alpha$ and IL- 6 compared with healthy controls $(37,38)$. In addition, blood monocytes from patients with psoriasis have unique gene signatures that contribute to the chronic inflammatory state (5). In the present study, MDSCs from patients with psoriasis were demonstrated to produce MMP9, MMP1, IL-8, GRO, and MCP-1. These molecules may contribute to recruitment of other inflammatory cells, including neutrophils and monocytes. Various cytokines and molecules are produced by myeloid lineage cells; this is consistent with the production by MDSC of molecules that may be involved in sustaining MDSC function and accumulation in a feedback mechanism, and in addition may contribute to the recruitment of other cell types, and skewing immune responses (8). MMPs, including MMP9 and MMP1, aid the migration of immune cells through tissue, and have been demonstrated to promote the accumulation of MDSC (39). IL-8 is a chemokine involved in recruitment and migration of neutrophils, $\mathrm{T}$ cells and basophils, and may act as an angiogenic factor (40). Similarly, MCP-1 is highly chemotactic for monocytes, T cells, basophils and NK cells (40). GRO may be involved in recruitment of neutrophils, may block differentiation of myeloid cells, and may induce production of immune suppressive cytokines by myeloid cells (41). These molecules may thus contribute to further accumulation of inflammatory cells, may provide a feedback mechanism that leads to accumulation of further regulatory or suppressive cells, and may have far reaching effects in other organ systems when produced in circulation by elevated levels of MDSC. The chronic inflammatory state in patients with psoriasis may contribute to the increased risk of comorbidities. Notably, molecules including MMP9, MMP1 and IL-8 have been implicated in the pathogenesis of atheromas and cardiovascular disease (42). As MDSCs accumulate in patients with acute coronary syndrome, this may indicate a potential association between these molecules, MDSCs, inflammation and cardiovascular disease (43).

MDSCs have been recognized in patients with various types of cancer and autoimmune diseases. The results of the present study demonstrated that patients with psoriasis have significantly elevated levels of MDSCs in circulation. These cells are a heterogeneous population of immature myeloid cells that have immunoregulatory function, and may produce various factors that contribute to the chronic inflammatory state in these patients. As novel therapeutics and targets are discovered for the treatment of psoriasis, the present study identified an additional potential immune network that may be important in the pathogenesis of the disease. 


\section{Acknowledgements}

Funding for the present study was awarded to D.I. from the Ostrow Graff Family Discovery Grant at the National Psoriasis Foundation. The authors would like to thank Dr Louis Falo and lab manager Miss Cara Carey, at the University of Pittsburgh Medical Center, for allowing the use of laboratory space and equipment to perform the experiments. This project used the University of Pittsburgh Cancer Institute Cancer Biomarkers Facility: Luminex Core Laboratory that is supported in part by the National Institutes of Health (grant no. P30CA047904), and the University of Pittsburgh Clinical and Translational Science Institute.

\section{References}

1. Ogdie A, Yu Y, Haynes K, Love TJ, Maliha S, Jiang Y, Troxel AB, Hennessy S, Kimmel SE, Margolis DJ, et al: Risk of major cardiovascular events in patients with psoriatic arthritis, psoriasis and rheumatoid arthritis: A population-based cohort study. Ann Rheum Dis 74: 326-332, 2015.

2. Chi CC, Wang J, Chen YF, Wang SH, Chen FL and Tung TH: Risk of incident chronic kidney disease and end-stage renal disease in patients with psoriasis: A nationwide population-based cohort study. J Dermatol Sci 78: 232-238, 2015

3. Wan J, Wang S, Haynes K, Denburg MR, Shin DB and Gelfand JM: Risk of moderate to advanced kidney disease in patients with psoriasis: Population based cohort study. BMJ 347: f5961, 2013.

4. Ganzetti G, Campanati A and Offidani A: Non-alcoholic fatty liver disease and psoriasis: So far, so near. World J Hepatol 7: 315-326, 2015.

5. Wang CQ, Suarez-Farinas M, Nograles KE, Mimoso CA, Shrom D, Dow ER, Heffernan MP, Hoffman RW and Krueger JG: IL-17 induces inflammation-associated gene products in blood monocytes, and treatment with ixekizumab reduces their expression in psoriasis patient blood. J Invest Dermatol 134: 2990-2993, 2014

6. Ilkovitch D: Role of immune-regulatory cells in skin pathology. J Leukoc Biol 89: 41-49, 2011

7. Ilkovitch D and Lopez DM: Urokinase-mediated recruitment of myeloid-derived suppressor cells and their suppressive mechanisms are blocked by MUC1/sec. Blood 113: 4729-4739, 2009.

8. Bronte V, Brandau S, Chen SH, Colombo MP, Frey AB, Greten TF, Mandruzzato S, Murray PJ, Ochoa A, Ostrand-Rosenberg S, et al: Recommendations for myeloid-derived suppressor cell nomenclature and characterization standards. Nat Commun 7: 12150, 2016.

9. Gabrilovich DI, Bronte V, Chen SH, Colombo MP, Ochoa A, Ostrand-Rosenberg S and Schreiber H: The terminology issue for myeloid-derived suppressor cells. Cancer Res 67: 425-426, 2007.

10. Liu C, Yu S, Kappes J, Wang J, Grizzle WE, Zinn KR and Zhang HG: Expansion of spleen myeloid suppressor cells represses NK cell cytotoxicity in tumor-bearing host. Blood 109: 4336-4342, 2007.

11. Sinha P, Clements VK, Bunt SK, Albelda SM and Ostrand-Rosenberg S: Cross-talk between myeloid-derived suppressor cells and macrophages subverts tumor immunity toward a type 2 response. J Immunol 179: 977-983, 2007.

12. Ilkovitch D and Lopez DM: The liver is a site for tumor-induced myeloid-derived suppressor cell accumulation and immunosuppression. Cancer Res 69: 5514-5521, 2009.

13. Huang B, Pan PY, Li Q, Sato AI, Levy DE, Bromberg J, Divino CM and Chen SH: Gr-1+CD115+ immature myeloid suppressor cells mediate the development of tumor-induced $\mathrm{T}$ regulatory cells and T-cell anergy in tumor-bearing host. Cancer Res 66: 1123-1131,2006.

14. Youn JI, Nagaraj S, Collazo M and Gabrilovich DI: Subsets of myeloid-derived suppressor cells in tumor-bearing mice. J Immunol 181: 5791-5802, 2008.

15. Filipazzi P, Valenti R, Huber V, Canese P, Iero M, Castelli C, Mariani L, Parmiani G and Rivoltini L: Identification of a new subset of myeloid suppressor cells in peripheral blood of melanoma patients with modulation by a granulocyte-macrophage colony-stimulation factor-based antitumor vaccine. J Clin Oncol 25: 2546-2553, 2007.
16. Diaz-Montero CM, Salem ML, Nishimura MI, Garrett-Mayer E, Cole DJ and Montero AJ: Increased circulating myeloid-derived suppressor cells correlate with clinical cancer stage, metastatic tumor burden, and doxorubicin-cyclophosphamide chemotherapy. Cancer Immunol Immunother 58: 49-59, 2009.

17. Almand B, Clark JI, Nikitina E, van Beynen J, English NR, Knight SC,Carbone DP and Gabrilovich DI: Increased production of immature myeloid cells in cancer patients: A mechanism of immunosuppression in cancer. J Immunol 166: 678-689, 2001.

18. Kusmartsev S, Su Z, Heiser A, Dannull J, Eruslanov E, Kübler H, Yancey D, Dahm P and Vieweg J: Reversal of myeloid cell-mediated immunosuppression in patients with metastatic renal cell carcinoma. Clin Cancer Res 14: 8270-8278, 2008

19. Hoechst B, Ormandy LA, Ballmaier M, Lehner F, Krüger C, Manns MP, Greten TF and Korangy F: A new population of myeloid-derived suppressor cells in hepatocellular carcinoma patients induces CD4(+)CD25(+)Foxp3(+) T cells. Gastroenterology 135: 234-243, 2008.

20. Haile LA, von Wasielewski R, Gamrekelashvili J, Krüger C, Bachmann O, Westendorf AM, Buer J, Liblau R, Manns MP, Korangy $\mathrm{F}$ and Greten TF: Myeloid-derived suppressor cells in inflammatory bowel disease: A new immunoregulatory pathway. Gastroenterology 135: 871-881.e1-5, 2008.

21. Makarenkova VP, Bansal V, Matta BM, Perez LA and Ochoa JB: $\mathrm{CD} 11 \mathrm{~b}+/ \mathrm{Gr}-1+$ myeloid suppressor cells cause $\mathrm{T}$ cell dysfunction after traumatic stress. J Immunol 176: 2085-2094, 2006.

22. Noel JG, Osterburg A, Wang Q, Guo X, Byrum D, Schwemberger S, Goetzman H, Caldwell CC and Ogle CK: Thermal injury elevates the inflammatory monocyte subpopulation in multiple compartments. Shock 28: 684-693, 2007.

23. Delano MJ, Scumpia PO, Weinstein JS, Coco D, Nagaraj S, Kelly-Scumpia KM, O'Malley KA, Wynn JL, Antonenko S, Al-Quran SZ, et al: MyD88-dependent expansion of an immature GR-1(+)CD11b(+) population induces $\mathrm{T}$ cell suppression and Th2 polarization in sepsis. J Exp Med 204: 1463-1474, 2007.

24. De Santo C, Salio M, Masri SH, Lee LY, Dong T, Speak AO, Porubsky S, Booth S, Veerapen N, Besra GS, et al: Invariant NKT cells reduce the immunosuppressive activity of influenza $A$ virus-induced myeloid-derived suppressor cells in mice and humans. J Clin Invest 118: 4036-4048, 2008.

25. Dugast AS, Haudebourg T, Coulon F, Heslan M, Haspot F, Poirier N, Vuillefroy de Silly R, Usal C, Smit H, Martinet B, et al: Myeloid-derived suppressor cells accumulate in kidney allograft tolerance and specifically suppress effector T cell expansion. J Immunol 180: 7898-7906, 2008.

26. Soler DC, Young AB, Fiessinger L, Galimberti F, Debanne S, Groft S, McCormick TS and Cooper KD: Increased, but functionally impaired, CD14(+) HLA-DR(-/low) myeloid-derived suppressor cells in psoriasis: A mechanism of dysregulated T cells. J Invest Dermatol 136: 798-808, 2016.

27. Yang L, DeBusk LM, Fukuda K, Fingleton B, Green-Jarvis B, Shyr Y, Matrisian LM, Carbone DP and Lin PC: Expansion of myeloid immune suppressor $\mathrm{Gr}+\mathrm{CD} 11 \mathrm{~b}+$ cells in tumor-bearing host directly promotes tumor angiogenesis. Cancer Cell 6: 409-421, 2004.

28. Nefedova Y, Fishman M, Sherman S, Wang X, Beg AA and Gabrilovich DI: Mechanism of all-trans retinoic acid effect on tumor-associated myeloid-derived suppressor cells. Cancer Res 67: 11021-11028, 2007.

29. Talmadge JE and Gabrilovich DI: History of myeloid-derived suppressor cells. Nat Rev Cancer 13: 739-752, 2013.

30. Kotsakis A, Harasymczuk M, Schilling B, Georgoulias V, Argiris A and Whiteside TL: Myeloid-derived suppressor cell measurements in fresh and cryopreserved blood samples. J Immunol Methods 381: 14-22, 2012.

31. Gehad AE, Lichtman MK, Schmults CD, Teague JE, Calarese AW, Jiang Y, Watanabe R and Clark RA: Nitric oxide-producing myeloid-derived suppressor cells inhibit vascular E-selectin expression in human squamous cell carcinomas. J Invest Dermatol 132: 2642-2651, 2012.

32. Mendoza AE, Neely CJ, Charles AG, Kartchner LB, Brickey WJ, Khoury AL, Sempowski GD, Ting JP, Cairns BA and Maile R: Radiation combined with thermal injury induces immature myeloid cells. Shock 38: 532-542, 2012.

33. Marhaba R, Vitacolonna M, Hildebrand D, Baniyash M, Freyschmidt-Paul P and Zöller M: The importance of myeloid-derived suppressor cells in the regulation of autoimmune effector cells by a chronic contact eczema. J Immunol 179: 5071-5081, 2007. 
34. Skabytska Y, Wolbing F, Günther C, Köberle M, Kaesler S, Chen KM, Guenova E, Demircioglu D, Kempf WE, Volz T, et al: Cutaneous innate immune sensing of Toll-like receptor 2-6 ligands suppresses $\mathrm{T}$ cell immunity by inducing myeloid-derived suppressor cells. Immunity 41: 762-775, 2014.

35. Guan Q, Moreno S, Qing G, Weiss CR, Lu L, Bernstein CN, Warrington RJ, Ma Y and Peng Z: The role and potential therapeutic application of myeloid-derived suppressor cells in TNBS-induced colitis. J Leukoc Biol 94: 803-811, 2013.

36. Smith AR and Reynolds JM: Editorial: The contribution of myeloid-derived suppression to inflammatory disease. J Leukoc Biol 96: 361-364, 2014.

37. Mizutani H, Ohmoto Y, Mizutani T, Murata M and Shimizu M: Role of increased production of monocytes TNF-alpha, IL-1beta and IL-6 in psoriasis: Relation to focal infection, disease activity and responses to treatments. J Dermatol Sci 14: 145-153, 1997.

38. Okubo Y and Koga M: Peripheral blood monocytes in psoriatic patients overproduce cytokines. J Dermatol Sci 17: 223-232, 1998.
39. Melani C, Sangaletti S, Barazzetta FM, Werb Z and Colombo MP: Amino-biphosphonate-mediated MMP-9 inhibition breaks the tumor-bone marrow axis responsible for myeloid-derived suppressor cell expansion and macrophage infiltration in tumor stroma. Cancer Res 67: 11438-11446, 2007.

40. Ilkovitch D and Lopez DM: Immune modulation by melanoma-derived factors. Exp Dermatol 17: 977-985, 2008.

41. Chen HW, Chen HY, Wang LT, Wang FH, Fang LW, Lai HY, Chen HH, Lu J, Hung MS, Cheng Y, et al: Mesenchymal stem cells tune the development of monocyte-derived dendritic cells toward a myeloid-derived suppressive phenotype through growth-regulated oncogene chemokines. J Immunol 190: 5065-5077, 2013

42. Mehra VC, Ramgolam VS and Bender JR: Cytokines and cardiovascular disease. J Leukoc Biol 78: 805-818, 2005.

43. Wang YG, Xiong X, Chen ZY, Liu KL, Yang JH, Wen Q, Wu FQ, Hu XF, Peng YD, Wu JJ, et al: Expansion of myeloid-derived suppressor cells in patients with acute coronary syndrome. Cell Physiol Biochem 35: 292-304, 2015. 